\title{
Autoimmune Gastritis and Gastric Microbiota
}

\author{
Laura Conti, Bruno Annibale ${ }^{\mathbb{D}}$ and Edith Lahner* ${ }^{\mathbb{D}}$
}

Medical-Surgical Department of Clinical Sciences and Translational Medicine, Sant'Andrea Hospital, Sapienza University of Rome, via di Grottarossa 1035, 00189 Rome, Italy; lau88.conti@gmail.com (L.C.); bruno.annibale@uniroma1.it (B.A.)

* Correspondence: edith.lahner@uniroma1.it; Tel.: +39-0633775695 (L.C. \& B.A. \& E.L.)

Received: 9 October 2020; Accepted: 17 November 2020; Published: 19 November 2020

\begin{abstract}
Autoimmune atrophic gastritis is an organ-specific immune-mediated condition characterized by atrophy of the oxyntic mucosa. Autoimmune atrophic gastritis (AIG) is characterized by a progressive loss of acid-secreting parietal cells leading to hypo-achlorhydria. Due to this peculiar intra-gastric environment, gastric microbiota composition in individuals with autoimmune atrophic gastritis was first supposed and then recently reported to be different from subjects with a normal acidic healthy stomach. Recent data confirm the prominent role of Helicobacter pylori as the main bacterium responsible for gastric disease and long-term complications. However, other bacteria than Helicobacter pylori, for example, Streptococci, were found in subjects who developed gastric cancer and in subjects at risk of this fearful complication, as well as those with autoimmune gastritis. Gastric microbiota composition is challenging to study due to the acidic gastric environment, the difficulty of obtaining representative samples of the entire gastric microbiota, and the possible contamination by oral or throat microorganisms, which can potentially lead to the distortion of the original gastric microbial composition, but innovative molecular approaches based on the analysis of the hyper-variable region of the $16 \mathrm{~S}$ rRNA gene have been developed, permitting us to obtain an overall microbial composition view of the RNA gene that is present only in prokaryotic cells.
\end{abstract}

Keywords: autoimmune gastritis; atrophic gastritis; gastric microbiota

\section{Introduction}

Autoimmune atrophic gastritis (AIG) is a relatively frequent and often undiagnosed disorder with important and potentially life-threatening consequences from a clinical point of view, ranging from micronutrient deficiencies and severe anemia to such neoplastic complications as gastric cancer and gastric type 1 neuroendocrine tumors. Due to its peculiar intra-gastric environment, characterized by severely impaired gastric acid secretion as a result of gastric oxyntic mucosa atrophy, the gastric microbiota composition in individuals with AIG was first supposed and then recently reported to be different from subjects with a normal acidic stomach, possibly assuming a key role in the development of neoplastic complications. This evidence adds new pieces to a constantly developing puzzle on the knowledge of autoimmune atrophic gastritis, a condition far from being completely investigated, and opens the door to new and intriguing perspectives on the management and possible treatment options of this important condition, which reduces the quality of life of millions of persons all over the world. This review addresses different aspects of AIG, focusing particularly on epidemiology, the clinical picture and management, the relationship between hypochlorhydria and long-term complications, and the interplay between the gastric microbiota, autoimmune gastritis and its clinical consequences, as well as the complicated and still debated role of Helicobacter pylori infection, providing an updated summary of recent scientific evidence on this intriguing topic. 


\section{Epidemiology and Clinical Manifestations of Autoimmune Gastritis}

AIG is an organ-specific immune-mediated condition that affects the corpus and fundus of the stomach; AIG is characterized by atrophy of the oxyntic mucosa with subsequent hypochlorhydria, hypergastrinemia, and deficiency of intrinsic factors, leading, in late stages, to pernicious anemia [1]. AIG's classical histopathological alterations consist of corporal-limited Helicobacter pylori (Hp)-negative atrophic gastritis with a spared antrum; sometimes, active Hp infection and/or involved antral mucosa may be observed in AIG, showing overlapping features with the multifocal atrophic gastritis mainly linked to Hp [2]. AIG is a condition that may involve any age group, but more frequently affects the elderly and females; most cases are reported in subjects of Northern European descent [3]. The absence of proactive case-finding strategies for AIG diagnosis, the lack of epidemiological studies, and the frequent indolent disease course, possibly leading to an underestimation of the disease, may contribute to the lack of knowledge of the true prevalence of AIG [4]. Moreover, in most papers published in the recent past, AIG was diagnosed only based on serological biomarkers such as anti-parietal cell or anti-intrinsic factor antibodies (PCA/IFA), pepsinogen, and/or gastrin-17 levels [5,6] without any histological confirmatory diagnosis. Finally, for several years, the diagnosis of AIG was frequently underestimated and mistakenly considered only in cases of pernicious anemia (PA), with macrocytic anemia due to vitamin $B_{12}$ malabsorption usually manifesting itself in the late stage of the disease $[7,8]$. Based on this scenario, AIG prevalence has been estimated to be $\sim 0.5-4.5 \%$ globally, varying widely owing to different diagnostic criteria, ethnical and demographical settings [4].

From a pathological point of view, AIG is thought to be the result of a complex interaction between environmental factors and host-related factors such as genetic susceptibility, but data are scant. An Italian study showed a significantly higher prevalence of HLA-DRB ${ }^{*} 03$ and HLA-DRB1 ${ }^{*} 04$ alleles in patients with AIG than in a healthy control group [9]. By contrast, a Finnish study found an association between AIG and HLA-DRB1*04/HLA-DQB1*03, but not with HLA-DRB1*03 [10]. These HLA haplotypes are also frequently associated with other autoimmune diseases, in particular autoimmune thyroid disease, thereby underlining a common HLA-dependent autoimmune pathway [4].

Despite the advancements in knowledge that have been made in the field of AIG, the trigger precipitating the autoimmune response has not been clarified. The resulting immunological dysregulations involve sensitized CD4+T lymphocytes and PCA/IFA, while gastric corpus/fundus tissue damage results from an antibody-mediated destruction of the parietal cells due to selective targeting of the $\mathrm{H}+/ \mathrm{K}+$ ATPase proton pump [11]. PCA are of immunoglobulin $\mathrm{G}$ type, they are directed against the parietal cell $\mathrm{H}+/ \mathrm{K}+$ ATPase, and they are mainly considered serological markers of autoimmune gastritis. PCA/IFA positivity is considered a helpful tool for AIG diagnosis. However, detection of those antibodies is not sufficient for AIG diagnosis, because they are not specific and are also found in healthy individuals for in escaped negative thymic selection or in patients with other autoimmune diseases such as type 1 diabetes or thyroid diseases, whereby the AIG prevalence is comparatively three- to fivefold higher [12].

Furthermore, serology against $\mathrm{H}$. pylori (IgG AbHp) may be positive in AIG patients with previous contact with the bacterium or in those previously treated for the infection. When a positive serological titer of $\mathrm{AbHp}$ is found in a patient with AIG together with a polymorphonucleate inflammatory infiltrate in the gastric mucosa, an active $\mathrm{H}$. pylori infection should be suspected [13].

From a clinical point of view, AIG has been traditionally considered a silent condition, often suspected due to its hematologic findings, and rarely by the presence of gastrointestinal symptoms. Despite the fact that most patients are pauci- or asymptomatic, several studies have shown that dyspeptic symptoms such as postprandial fullness, early satiety, and nausea are among the most common symptoms complained about by AIG patients [14-16]. Most commonly, AIG may be suspected in the presence of an iron deficiency and, in particular, anemia due to iron malabsorption consequent to reduced gastric acid secretion (25-50\% of patients with AIG) or, rarely, in the presence of pernicious anemia, which is found in up to $15-25 \%$ of AIG patients [17-20]. Less frequently, AIG patients may complain of neurological symptoms such as paresthesia, abnormal proprioception, numbness, ataxia, 
cognitive impairment, mood disorders, and psychosis. Neurological symptoms are consequences of vitamin $B_{12}$ deficiency, due to an impairment of sensory and peripheral nerve function linked to a reduced production of succinyl coenzyme A, which is essential for myelin sheath structure [21,22]. Finally, concomitant autoimmune diseases, especially Hashimoto thyroiditis or a positive family history for AIG may contribute to increasing the suspicion of an AIG diagnosis.

\section{Association with Other Autoimmune Diseases}

AIG may be associated with a wide spectrum of autoimmune disorders [4]. Hashimoto thyroiditis (HT) is the most frequent autoimmune disease associated with AIG with a 3-8-fold higher reported prevalence than in the general population [23]. Conversely, the prevalence of AIG is 3-5 times greater in patients with autoimmune thyroid disorders $[3,5,6]$. The association between gastric and thyroid disorders has been observed since the early 1960s when the frequent co-presence of the thyroid and gastric autoantibodies (anti-thyroperoxidase, anti-thyroglobulin, PCA, IFA) in patients with thyroid disorders and PA led Doniach B and Irvine WJ et al. to coin the expression "thyrogastric syndrome" [24-27]. The impairment of thyroid follicular cells and gastric parietal cells typical of HT and AIG are, respectively, due to a multifactorial etiology resulting from the association between genetic susceptibility and several environmental factors $[28,29]$. The specific mechanism leading to thyrocytes and/or parietal cell damage is still poorly understood, but this similar phenomenon can be partly elucidated by the common embryological origin of gastric mucosal and thyroid follicular cells, both developing from the endoderm and sharing some functional and morphological similarities [30,31]. Thyro-gastric autoimmunity is currently considered part of type III polyglandular autoimmune syndromes, which include several endocrine and nonendocrine autoimmune disorders as a consequence of immune tolerance loss [27,32,33]. Type I diabetes mellitus (T1DM) is the second most frequently autoimmune disorder associated with AIG. This association has been confirmed by several studies which, found PCA positivity in $10-15 \%$ of children ( $<18$ years of age) and in $15-25 \%$ of adult T1DM patients [34,35]. Another study showed that 57\% of PCA-positive patients and 10\% of PCA-negative patients, out of 88 patients with T1DM (of whom 47 were PCA- positive) undergoing gastroscopy with biopsies, received a histological diagnosis of AIG [36]. Apart from HT and T1DM, the other less commonly associated autoimmune disorders are vitiligo and Addison's disease, followed by only sparse and scant data mainly resulting from case reports on the association between AIG and rheumatoid arthritis [37], celiac disease [38], and many other autoimmune disorders [39,40].

\section{The Role of Hypochlorhydria and Long-Term Complications}

Gastric acidity has several primary functions as a bactericidal defensive barrier, including digestive and absorptive properties. The progressive destruction of hydrochloric acid-secreting parietal cells is typical of AIG and may lead to a gradual hypochlorhydric state [1]. Hypochlorhydria may result in dietary iron malabsorption [41]. The $\mathrm{pH}$ increase due to the weakening of the gastric acid defensive barrier may also result in consequent gastric microbiota composition alterations with potential overgrowth of other bacteria than Hp [42]. Furthermore, AIG is considered a precancerous condition with an increased neoplasm risk, and is also linked to possible intra-gastric changes such as hypochlorhydria and increased oxidative stress as a consequence of persistent inflammatory infiltration of the corpus-fundus of the stomach [43]. The hypochlorhydric state may induce enterochromaffin-like (ECL) cell hyperplasia with a major risk of developing type 1 gastric neuroendocrine tumors over time, at percentages varying from $0.4 \%$ to $7 \%$, and gastric adenocarcinoma, with an incidence ranging between $0 \%$ and $1.8 \%$ per year [44-46]. The crucial role of parietal cell secretion in maintaining an acidic intragastric milieu is strictly regulated by both endocrinal and neuronal stimulation via the vagus nerve. Hydrochloric acid secretion is stimulated by gastrin, secreted by gastrin-producing cells in the antrum, and by histamine, produced by ECL cells in the corpus or fundus glands. In the presence of oxyntic mucosa atrophy, hypochlorhydria leads to persistently increased levels of gastrin, a well-known risk factor for ECL cell hyperplasia, dysplasia, and type 1 gastric neuroendocrine 
tumors [20,47]. While the higher risk of gastric cancer in corpus atrophic gastritis is well defined and linked to $\mathrm{Hp}$, considered the first trigger of a multistep carcinogenic process explained by the Correa Cascade [48], the potential carcinogenic mechanisms associated with AIG are still under debate. In fact, it has been hypothesized that inflammation, dysregulation of the host immune system, and an increase in nitrate and nitrose-producing bacteria, leading to a non-acidic intragastric milieu, as occurs in AIG, may play a role in gastric carcinogenesis [49-51]. Nowadays, most of the available evidence about the gastric cancer risk associated with AIG is derived from cohort and case-control studies conducted on patients affected by PA [52-57]. According to the recently published European guidelines on the management of epithelial precancerous conditions and lesions, AIG is considered a precancerous condition, and patients should be stratified according to risk groups (OLGA/OLGIM system, family history of gastric cancer, or presence of incomplete intestinal metaplasia) and monitored by gastroscopy with biopsies, according to the updated Sydney system protocol [8], at an interval of 3-5 years [58]. Lastly, the most frequent long-term complication associated with the hypochlorhydric state is the onset of hematological alterations due to iron or vitamin $\mathrm{B}_{12}$ malabsorption. Iron absorption is strictly dependent on normal gastric hydrochloric acid secretion, which is essential for the reduction of ferric dietary iron to ferrous iron, a major absorbable iron form $[59,60]$. Patients with iron-deficiency anemia may be managed by oral iron supplementation and it has been suggested to switch to intravenous iron delivery and blood transfusion only in case of severe anemia or exceptional situations $[4,61,62]$. In the case of vitamin $B_{12}$ deficiency, intramuscular administration is recommended to obtain an ideal vitamin $\mathrm{B}_{12}$ normalization, particularly in patients who complained of neurological symptoms, which are also not always reversible. For maintenance therapy, a Cochrane review did not find any superiority of oral or intramuscular vitamin $\mathrm{B}_{12}$ treatment in normalizing serum vitamin $\mathrm{B}_{12}$ levels, showing cost-effectiveness in favor of oral treatment, but the trials reviewed included patients irrespective of the cause of vitamin $B_{12}$ deficiency and therefore also patients without AIG or PA [63].

\section{Gastric Microbiota: Historical Aspects and Helicobacter pylori}

A growing body of literature on gastric microbiota composition has been recently published, but data in this field are still scarce and conflicting. Nowadays, no specific gastric microbiota profiles related to different gastric conditions such as Hp gastritis, chronic atrophic gastritis, autoimmune gastritis, or gastric cancer have been well defined [64]. The stomach was historically considered a sterile organ and an unfavorable bacterial growth environment owing to its very low $\mathrm{pH}$ and the proteolytic activity of gastric juice, as well as the antimicrobial function of nitric oxide, produced by salivary nitrate [65]. The discovery of $\mathrm{Hp}$ about 40 years ago was the first step towards a paradigm shift [66]. Hp infection was recognized to be the major cause of chronic atrophic gastritis, becoming the most thoroughly investigated component of the gastric microbiota [67], and it was classified as a class I carcinogen by the World Health Organization [68] for its contribution to gastric carcinogenesis, as supposed by Correa Cascade [48]. After Hp discovery, the growing interest in gastric histology and microbiology increased over time and many of the older observations, such as the effect of reduced acid secretion on promoting a diverse gastric flora, began to be investigated [69]. A growing number of culture-dependent and molecular method-based studies comparing different microbial compositions in Hp-positive or -negative subjects, in chronic atrophic gastritis and in stomachs with gastric cancer, were published, aiming to assess gastric microbiota diversity and its possible role in gastric carcinogenesis [70].

\section{The Role of Innovative Methods for the Detection of the Gastric Microbiota}

The interest in the field of gastric microbiota has been widely increasing in recent years. The knowledge of the gastric microbiota and its role in human health and diseases, although still limited, is expanding more and more thanks to the development of molecular-based methods [65]. Gastric microbiota composition is challenging to study, owing to the acidic gastric environment, the difficulty in obtaining a representative sample of the entire gastric microbiota by gastric biopsies or gastric juice 
samples, and their possible contamination by oral or throat microorganisms, which can potentially lead to the distortion of the microbial composition [67]. In 1946, Barber and Franklin published their efforts to culture bacteria from gastric mucosal swabs for the first time in history [71]. This study began the culture-dependent era of gastric microbiota definition. Unfortunately, the culture-based approach has several limitations and it is influenced by many factors comprising the type of gastric sample that is most often limited to luminal contents rather than mucosa-associated organisms, the different gastric acidic state of the stomach the time of the culture, and the methods used for culture [72]. However, the major limitation of the culture-based approach that the vast majority $(\sim 80 \%)$ of microbial species are not cultivable [73]. These limits and, in particular, the need to exceed the limit of non-cultivable microorganisms led to the development of new molecular techniques based first on DNA genome sequencing and then on next-generation sequencing and molecular analysis of microbiota [74]. Furthermore, the main advantage of culture-independent methods is the selective detection of viable bacteria. In the era of culture-independent methods, molecular approaches allowed researchers to markedly enhance the study of the gastrointestinal tract in general and the gastric microbiota profile in detail using DNA-based approaches, either relying on whole-genome information or focusing on the $16 \mathrm{~S}$ rRNA gene as a standard phylogenetic marker $[67,75]$. Methods relying on the sequence-specific separation of equal-sized 16S rDNA PCR-amplified fragments such as denaturing gradient gel electrophoresis (DGGE), temporal gradient gel electrophoresis (TTGE), or terminal restriction fragment length polymorphism (TRFLP) of polymerase chain reaction (PCR)-amplified 16S rDNA fragments were introduced in 2000 [72,76]. However, the above-cited methods were not able to define sequence differences at the species level and often relied on short $16 \mathrm{~S}$ rDNA-amplified fragments. Due to these limitations, they were successively replaced in the mid-2000s by a next-generation sequencing technique based on high-throughput DNA sequencing techniques, allowing researchers to assess the bacterial composition rapidly in many samples with greater sequencing depth and sequence coverage. The first study using high-throughput DNA sequencing techniques to analyze the human gastric mucosa microbiota was published in 2008, reporting a higher gastric microbiota diversity in Hp-negative compared to Hp-positive patients [77]. Since then, many other studies showed that Hp eradication may lead to increased bacterial diversity and restore the relative abundance of other bacteria similar to Hp-negative subjects, suggesting that Hp colonization results in alterations to the gastric microbiota, which are reversible by antibiotic treatment [78]. More recently, many innovative molecular approaches based on analyses of the hyper-variable region of the 16S rRNA gene by 16S rRNA gene-restricting high-throughput sequencing methods (Illumina, and Ion Torrent) have been developed, permitting us to obtain an overall microbial composition view of RNA that is only present in prokaryotic cells [74]. The gastric microbiota analysis based on 16S rRNA gene-restricting high-throughput sequencing methods has permitted us to identify many unexpected or previously unknown bacteria in Hp-negative stomachs with 262 phylotypes representing 13 phyla $[65,79]$. This technology allows us to analyze microbiota composition below the genus level, but only provides information on the bacterial presence, without any detail about bacterial functions or the vitality state of microorganisms [80]. Based on this scenario, the future goal is to perform studies assessing the metabolically active bacteria of the stomach using many innovative and different methods such as reverse-transcribed 16S rRNA as an amplification template [81].

\section{Gastric Microbiota, Hypochlorhydria, and Autoimmune Gastritis}

In recent years, several studies have been published in the field of gastric microbiota aiming to discover whether substantial differences between a healthy stomach and pathological gastric conditions were found. For this purpose, most of the authors working in this field have conducted studies mainly on the gastric microbiota of patients with gastric cancer, a well-known long-term complication of Hp-related atrophic gastritis, and AIG. Concerning gastric precancerous conditions, gastric microbiota composition of Hp-related atrophic gastritis has been better defined than that of AIG. Hp-induced atrophic gastritis has been reported to display a lower bacterial diversity and a decreased abundance of 
other microbial groups than a healthy stomach with a high prevalence of Proteobacteria (as Hp itself is a member of this phylum), as shown in previous studies [82,83]. However, this seems to be a reversible situation that may substantially change after Hp eradication. Apart from Hp, a well-established carcinogen linked to gastric cancer, the composition of the gastric microbiota has not yet been investigated thoroughly and conflicting data have emerged from different studies. Moreover, it should be noted that most of the data derive from Asian populations and only rarely from Western populations, and that different sources of gastric samples, different microbial composition-analyzing methods, as well as different reference groups have been used, such as chronic gastritis instead of a healthy stomach, in many studies [65,84-86]. A recently published systematic review on the gastric microbiota showed highly heterogeneous results for gastric microbial composition, with 266 bacterial genera identified, of which 57 were more frequently reported in the normal acidic stomach and distributed among five bacterial phyla, including Proteobacteria, Firmicutes, Bacteroidetes, Actinobacteria, Fusobacteria, and the most abundant genera: Helicobacter, Streptococcus, and Prevotella [65].

Considering gastric conditions characterized by a hypochlorhydric state and, in particular, corpus-restricted AIG, where the gastric mucosal barrier becomes progressively compromised due to an immune-mediated pathological mechanism, it has been hypothesized that the progressive loss of the acid barrier function may favor a bacterial overgrowth, thus potentially affecting the gastric microbiota composition; however, data in this field are currently scarce and conflicting (Figure 1) [42,65]. A previous study published by Parsons et al. focused on assessing the diversity of gastric microbial profiles in different hypochlorhydric states, including Hp-induced atrophic gastritis and AIG. This study showed that patients with AIG presented a relatively higher microbial diversity and bacterial abundance than normal stomachs with the largest proportion of Streptococci among the groups investigated [42]. Research on gastric microbiota in AIG is therefore at an early stage. As it has recently been accepted as a precancerous condition to be subjected to endoscopic surveillance for its potential neoplastic complications, further studies are needed to understand if changes in the gastric microbiota could be associated with the progression of gastric carcinogenesis [72].

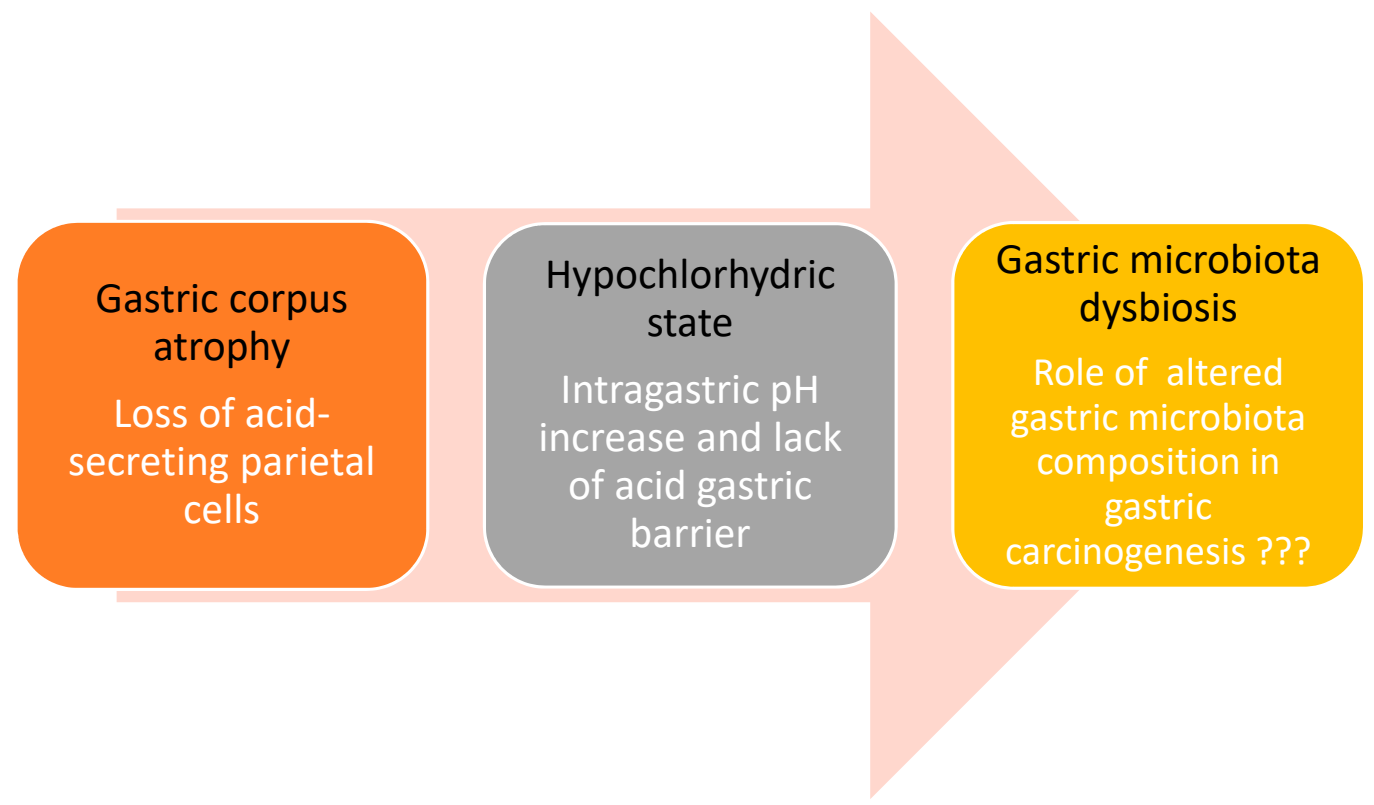

Figure 1. A possible link between autoimmune gastritis, hypochlorhydria, and gastric cancer may be hypothesized. Autoimmune gastritis, a corpus-restricted Hp-negative atrophic gastritis, is characterized by progressive immune-mediated atrophy of the oxyntic mucosa with subsequent loss of acid-secreting parietal cells, leading to hypochlorhydria. This changed intra-gastric microenvironment can make possible the survival of other bacteria than Hp possibly playing a key role in gastric carcinogenesis. 
Regarding the gastric microbiota in subjects with gastric cancer, most studies have shown that it seems to be characterized by an enrichment of bacterial diversity due to the additional colonization of the gastric environment by oral taxa [84,87] such as Streptococcus, Staphylococcus, Lactococcus, Bacillus, Prevotella, Veillonella, and Leptotrichia, as well as intestinal taxa such as Lactobacillus [88], Clostridium and Fusobacterium, with a contemporary decreased presence of Hp [84,85,89]. Interestingly, in the above-cited study on AIG, in individuals with this condition, who are predisposed to gastric cancer, the largest proportion of Streptococci was found; these microbes notably belong to the oral microbiota and, probably, the non-acidic gastric environment due to the fact that hypochlorhydria offers an acceptable habitat, making this oral commensal intriguing because plays a potential role in gastric carcinogenesis. However, conflicting data have been found in Portuguese studies, in which a decrease in Streptococcus in individuals with gastric cancer was reported $[70,85,90]$.

\section{Conclusions Remarks and Research Agenda}

As in other body districts, in the stomach, growing knowledge of the possible role of the microbiota in health and disease is emerging from recent studies. Recent data confirm the prominent role of $\mathrm{Hp}$ as the main bacterium responsible for gastric disease and long-term complications. However, other bacteria, and possibly other poorly or not yet investigated viral or fungal microbiota components, are emerging and likely play a role in conditions with an altered intragastric environment such as AIG, which is notably characterized by a non-acidic stomach favoring the overgrowth of microorganisms that are otherwise not viable in the acidic stomach. Some of these bacteria, for example, Streptococci, are found in subjects who have developed gastric cancer and in subjects at risk of this fearful complication, such as those with AIG. These first pieces of evidence certainly cannot be interpreted as a point of arrival, but should rather be viewed as a starting point for future research in this very complex and intriguing field in which much work is yet to be done. In the last few years, many pieces have been added to the knowledge puzzle, and future research is needed. As detailed in Table 1, several aspects are still awaiting clarification, to ultimately pave the way for possible innovative treatment strategies to eventually prevent the progression of AIG or neoplastic complications by therapeutic gastric microbiota modulation.

Table 1. Proposal of research agenda on gastric microbiota.

1 To standardize techniques and gastric samples used to assess the viable microbiota in the stomach by giving priority to innovative methods based on RNA for sequencing

2 To perform studies considering possible confounding factors on the gastric microbiota such as drugs and dietary, smoking, and alcohol habits

3 To perform longitudinal, multicentre studies to increase the knowledge on the role of gastric microbiota in gastric carcinogenesis

4 To launch studies on the gastric microbiota in Caucasian populations as the available data on Asian populations may not be necessarily comparable and valid in non-Asian subjects

Author Contributions: L.C. and E.L. drafted the manuscript; B.A. supervised and contributed to the completion of the draft. All authors have read and agreed to the published version of the manuscript.

Funding: This research received no external funding.

Conflicts of Interest: The authors declare no conflict of interest.

\section{References}

1. Rugge, M.; Correa, P.; Dixon, M.F.; Fiocca, R.; Hattori, T.; Lechago, J.; Leandro, G.; Price, A.B.; Sipponen, P.; Solcia, E.; et al. Gastric mucosal atrophy: Interobserver consistency using new criteria for classification and grading. Aliment. Pharmacol. Ther. 2002, 16, 1249-1259. [CrossRef] [PubMed] 
2. Lahner, E.; Zagari, R.M.; Zullo, A.; Di Sabatino, A.; Meggio, A.; Cesaro, P.; Lenti, M.V.; Annibale, B.; Corazza, G.R. Chronic atrophic gastritis: Natural history, diagnosis and therapeutic management. A position paper by the Italian Society of Hospital Gastroenterologists and Digestive Endoscopists [AIGO], the Italian Society of Digestive Endoscopy [SIED], the Italian Society of Gastroenterology [SIGE], and the Italian Society of Internal Medicine [SIMI]. Dig. Liver Dis. 2019, 51, 1621-1632. [PubMed]

3. Massironi, S.; Zilli, A.; Elvevi, A.; Invernizzi, P. The changing face of chronic autoimmune atrophic gastritis: An updated comprehensive perspective. Autoimmun. Rev. 2019, 18, 215-222. [CrossRef] [PubMed]

4. Lenti, M.V.; Rugge, M.; Lahner, E.; Miceli, E.; Toh, B.-H.; Genta, R.M.; De Block, C.; Hershko, C.; Di Sabatino, A. Autoimmune gastritis. Nat. Rev. Dis. Primers 2020, 6, 56. [CrossRef]

5. Toh, B.-H. Diagnosis and classification of autoimmune gastritis. Autoimmun. Rev. 2014, 13, 459-462. [CrossRef]

6. Rusak, E.; Chobot, A.; Krzywicka, A.; Wenzlau, J. Anti-parietal cell antibodies-Diagnostic significance. Adv. Med. Sci. 2016, 61, 175-179. [CrossRef]

7. Toh, B.-H.; Alderuccio, F. Pernicious anaemia. Autoimmunity 2004, 37, 357-361. [CrossRef]

8. Dixon, M.F.; Genta, R.M.; Yardley, J.H.; Correa, P. Classification and grading of gastritis. The updated Sydney System. International Workshop on the Histopathology of Gastritis, Houston 1994. Am. J. Surg. Pathol. 1996, 20, 1161-1181. [CrossRef]

9. Lahner, E.; Spoletini, M.; Buzzetti, R.; Corleto, V.D.; Vannella, L.; Petrone, A.; Annibale, B. HLA-DRB1*03 and DRB1*04 are associated with atrophic gastritis in an Italian population. Dig. Liver Dis. 2010, 42, 854-859. [CrossRef]

10. Oksanen, A.M.; Haimila, K.E.; Rautelin, H.I.K.; Partanen, J.A. Immunogenetic characteristics of patients with autoimmune gastritis. World J. Gastroenterol. 2010, 16, 354-358. [CrossRef]

11. Coati, I.; Fassan, M.; Farinati, F.; Graham, D.Y.; Genta, R.M.; Rugge, M. Autoimmune gastritis: Pathologist's viewpoint. World J. Gastroenterol. 2015, 21, 12179-12189. [CrossRef] [PubMed]

12. Conti, L.; Lenti, M.V.; Di Sabatino, A.; Miceli, E.; Galli, G.; Cazzato, M.; Falangone, F.; Annibale, B.; Edith Lahner, E. Seronegative autoimmune atrophic gastritis is more common in elderly patients. Dig. Liver Dis. 2020, 52, 1310-1314. [CrossRef] [PubMed]

13. Lahner, E.; Bordi, C.; Di Giulio, E.; Caruana, P.; D’Ambra, G.; Milione, M.; Grossi, C.; Delle Fave, G.; Annibale, B. Role of Helicobacter pylori serology in atrophic body gastritis after eradication treatment. Aliment. Pharmacol. Ther. 2002, 16, 507-514. [CrossRef] [PubMed]

14. Lenti, M.V.; Miceli, E.; Cococcia, S.; Klersy, C.; Staiani, M.; Guglielmi, F.; Giuffrida, P.; Vanoli, A.; Luinetti, O.; De Grazia, F.; et al. Determinants of diagnostic delay in autoimmune atrophic gastritis. Aliment. Pharmacol. Ther. 2019, 50, 167-175. [CrossRef] [PubMed]

15. Carabotti, M.; Lahner, E.; Esposito, G.; Sacchi, M.C.; Severi, C.; Annibale, B. Upper gastrointestinal symptoms in autoimmune gastritis: A cross-sectional study. Medicine (Baltim.) 2017, 96, e5784. [CrossRef] [PubMed]

16. Lahner, E.; Carabotti, M.; Esposito, G.; Hassan, C.; Zullo, A.; Annibale, B. Occurrence and predictors of metaplastic atrophic gastritis in a nation-wide consecutive endoscopic population presenting with upper gastrointestinal symptoms. Eur. J. Gastroenterol. Hepatol. 2018, 30, 1291-1296. [CrossRef]

17. Hunt, R.H.; Camilleri, M.; Crowe, S.E.; El-Omar, E.M.; Fox, J.G.; Kuipers, E.J.; Malfertheiner, P.; McColl, K.E.L.; Pritchard, D.M.; Rugge, M.; et al. The stomach in health and disease. Gut 2015, 64, 1650-1668. [CrossRef]

18. Hershko, C.; Ronson, A.; Souroujon, M.; Maschler, I.; Heyd, J.; Patz, J. Variable hematologic presentation of autoimmune gastritis: Age-related progression from iron deficiency to cobalamin depletion. Blood 2006, 107, 1673-1679. [CrossRef]

19. Lenti, M.V.; Lahner, E.; Bergamaschi, G.; Miceli, E.; Conti, L.; Massironi, S.; Cococcia, S.; Zilli, A.; Caprioli, F.; Vecchi, M.; et al. Cell Blood Count Alterations and Patterns of Anaemia in Autoimmune Atrophic Gastritis at Diagnosis: A Multicentre Study. J. Clin. Med. 2019, 8, 1992. [CrossRef]

20. Lahner, E.; Annibale, B. Pernicious anemia: New insights from a gastroenterological point of view. World J. Gastroenterol. 2009, 15, 5121-5128. [CrossRef]

21. Lindenbaum, J.; Healton, E.B.; Savage, D.G.; Brust, J.C.; Garrett, T.J.; Podell, E.R.; Marcell, P.D.; Stabler, S.P.; Allen, R.H. Neuropsychiatric disorders caused by cobalamin deficiency in the absence of anemia or macrocytosis. N. Engl. J. Med. 1988, 318, 1720-1728. [CrossRef] [PubMed]

22. Gwathmey, K.G.; Grogan, J. Nutritional neuropathies. Muscle Nerve 2020, 62, 13-29. [CrossRef] [PubMed] 
23. Hughes, J.W.; Muegge, B.D.; Tobin, G.S.; Litvin, M.; Sun, L.; Saenz, J.B.; Gyawali, C.P.; McGill, J.B. High-Risk Gastric Pathology and Prevalent Autoimmune Diseases in Patients with Pernicious Anemia. Endocr. Pract. 2017, 23, 1297-1303. [CrossRef] [PubMed]

24. Doniach, D.; Ro Itt, I.M.; Taylor, K.B. Autoimmune phenomena in pernicious anaemia. Serological overlap with thyroiditis, thyrotoxicosis, and systemic lupus erythematosus. Br. Med. J. 1963, 1, 1374-1379. [CrossRef]

25. Markson, J.L.; Moore, J.M. Thyroid Auto-antibodies in Pernicious Anaemia. Br. Med. J. 1962, 2, $1352-1355$. [CrossRef]

26. Carmel, R.; Spencer, C.A. Clinical and subclinical thyroid disorders associated with pernicious anemia. Observations on abnormal thyroid-stimulating hormone levels and on a possible association of blood group O with hyperthyroidism. Arch. Intern. Med. 1982, 142, 1465-1469. [CrossRef]

27. Lahner, E.; Conti, L.; Cicone, F.; Capriello, S.; Cazzato, M.; Centanni, M.; Annibale, B.; Virili, C. Thyro-entero-gastric autoimmunity: Pathophysiology and implications for patient management. Best Pract. Res. Clin. Endocrinol. Metab. 2019, 34, 101373. [CrossRef]

28. Toh, B.-H.; Chan, J.; Kyaw, T.; Alderuccio, F. Cutting edge issues in autoimmune gastritis. Clin. Rev. Allergy Immunol. 2012, 42, 269-278. [CrossRef]

29. Ragusa, F.; Fallahi, P.; Elia, G.; Gonnella, D.; Paparo, S.R.; Giusti, C.; Churilov, L.P.; Ferrari, S.M.; Antonelli, A. Hashimotos' thyroiditis: Epidemiology, pathogenesis, clinic and therapy. Best Pract. Res. Clin. Endocrinol. Metab. 2019, 33, 101367. [CrossRef]

30. Bliddal, S.; Nielsen, C.H.; Feldt-Rasmussen, U. Recent advances in understanding autoimmune thyroid disease: The tallest tree in the forest of polyautoimmunity. F1000Research 2017, 6, 1776. [CrossRef]

31. Venturi, S.; Donati, F.M.; Venturi, A.; Venturi, M.; Grossi, L.; Guidi, A. Role of iodine in evolution and carcinogenesis of thyroid, breast and stomach. Adv. Clin. Pathol. 2000, 4, 11-17.

32. Betterle, C.; Zanchetta, R. Update on autoimmune polyendocrine syndromes [APS]. Acta Biomed. 2003, 74, 9-33. [PubMed]

33. Husebye, E.S.; Anderson, M.S.; Kämpe, O. Autoimmune Polyendocrine Syndromes. N. Engl. J. Med. 2018, 378, 2543-2544. [CrossRef] [PubMed]

34. De Block, C.E.M.; De Leeuw, I.H.; Van Gaal, L.F. Autoimmune gastritis in type 1 diabetes: A clinically oriented review. J. Clin. Endocrinol. Metab. 2008, 93, 363-371. [CrossRef]

35. De Block, C.E.; De Leeuw, I.H.; Van Gaal, L.F. High prevalence of manifestations of gastric autoimmunity in parietal cell antibody-positive type 1 [insulin-dependent] diabetic patients. The Belgian Diabetes Registry. J. Clin. Endocrinol. Metab. 1999, 84, 4062-4067.

36. De Block, C.E.M.; De Leeuw, I.H.; Bogers, J.J.P.M.; Pelckmans, P.A.; Ieven, M.M.; Van Marck, E.A.E.; Van Acker, K.L.; Van Gaal, L.F. Autoimmune gastropathy in type 1 diabetic patients with parietal cell antibodies: Histological and clinical findings. Diabetes Care 2003, 26, 82-88. [CrossRef]

37. Miceli, E.; Lenti, M.V.; Padula, D.; Luinetti, O.; Vattiato, C.; Monti, C.M.; Di Stefano, M.; Corazza, G.R. Common features of patients with autoimmune atrophic gastritis. Clin. Gastroenterol. Hepatol. 2012, 10, 812-814. [CrossRef]

38. Nenna, R.; Magliocca, F.M.; Tiberti, C.; Mastrogiorgio, G.; Petrarca, L.; Mennini, M.; Lucantoni, F.; Luparia, R.P.L.; Bonamico, M. Endoscopic and histological gastric lesions in children with celiac disease: Mucosal involvement is not only confined to the duodenum. J. Pediatr. Gastroenterol. Nutr. 2012, 55, 728-732. [CrossRef]

39. Jevremovic, D.; Torbenson, M.; Murray, J.A.; Burgart, L.J.; Abraham, S.C. Atrophic autoimmune pangastritis: A distinctive form of antral and fundic gastritis associated with systemic autoimmune disease. Am. J. Surg. Pathol. 2006, 30, 1412-1419. [CrossRef]

40. Vanderlocht, J.; van der Cruys, M.; Stals, F.; Bakker-Jonges, L.; Damoiseaux, J. Multiplex autoantibody detection for autoimmune liver diseases and autoimmune gastritis. J. Immunol. Methods 2017, 448, 21-25. [CrossRef]

41. Cook, J.D.; Brown, G.M.; Valberg, L.S. The Effect of Achylia Gastrica on Iron Absorption. J. Clin. Investig. 1964, 43, 1185-1191. [CrossRef]

42. Parsons, B.N.; Ijaz, U.Z.; D’Amore, R.; Burkitt, M.D.; Eccles, R.; Lenzi, L.; Duckworth, C.A.; Moore, A.R.; Tiszlavicz, L.; Varro, A.; et al. Comparison of the human gastric microbiota in hypochlorhydric states arising as a result of Helicobacter pylori-induced atrophic gastritis, autoimmune atrophic gastritis and proton pump inhibitor use. PLoS Pathog. 2017, 13, e1006653. [CrossRef] [PubMed] 
43. Butcher, L.D.; den Hartog, G.; Ernst, P.B.; Crowe, S.E. Oxidative Stress Resulting From Helicobacter pylori Infection Contributes to Gastric Carcinogenesis. Cell. Mol. Gastroenterol. Hepatol. 2017, 3, 316-322. [CrossRef] [PubMed]

44. Zhang, H.; Jin, Z.; Cui, R.; Ding, S.; Huang, Y.; Zhou, L. Autoimmune metaplastic atrophic gastritis in chinese: A study of 320 patients at a large tertiary medical center. Scand. J. Gastroenterol. 2017, 52, 150-156. [CrossRef] [PubMed]

45. Vannella, L.; Sbrozzi-Vanni, A.; Lahner, E.; Bordi, C.; Pilozzi, E.; Corleto, V.D.; Osborn, G.F.; Delle Fave, G.; Annibale, B. Development of type I gastric carcinoid in patients with chronic atrophic gastritis. Aliment. Pharmacol. Ther. 2011, 33, 1361-1369. [CrossRef]

46. Lahner, E.; Esposito, G.; Pilozzi, E.; Purchiaroni, F.; Corleto, V.D.; Di Giulio, E.; Annibale, B. Occurrence of gastric cancer and carcinoids in atrophic gastritis during prospective long-term follow up. Scand. J. Gastroenterol. 2015, 50, 856-865. [CrossRef]

47. Annibale, B.; Azzoni, C.; Corleto, V.D.; di Giulio, E.; Caruana, P.; D’Ambra, G.; Bordi, C.; Delle Fave, G. Atrophic body gastritis patients with enterochromaffin-like cell dysplasia are at increased risk for the development of type I gastric carcinoid. Eur. J. Gastroenterol. Hepatol. 2001, 13, 1449-1456. [CrossRef]

48. Correa, P. Helicobacter pylori and gastric carcinogenesis. Am. J. Surg. Pathol. 1995, 19 (Suppl. 1), S37-S43.

49. Sobala, G.M.; Pignatelli, B.; Schorah, C.J.; Bartsch, H.; Sanderson, M.; Dixon, M.F.; Shires, S.; King, R.F.; Axon, A.T. Levels of nitrite, nitrate, N-nitroso compounds, ascorbic acid and total bile acids in gastric juice of patients with and without precancerous conditions of the stomach. Carcinogenesis 1991, 12, 193-198. [CrossRef]

50. Kishikawa, H.; Nishida, J.; Ichikawa, H.; Kaida, S.; Matsukubo, T.; Miura, S.; Morishita, T.; Hibi, T. Serum nitrate/nitrite concentration correlates with gastric juice nitrate/nitrite: A possible marker for mutagenesis of the proximal stomach. Digestion 2011, 84, 62-69. [CrossRef]

51. Ziebarth, D.; Spiegelhalder, B.; Bartsch, H. N-nitrosation of medicinal drugs catalysed by bacteria from human saliva and gastro-intestinal tract, including Helicobacter pylori. Carcinogenesis 1997, 18, 383-389. [CrossRef] [PubMed]

52. Hsing, A.W.; Hansson, L.E.; McLaughlin, J.K.; Nyren, O.; Blot, W.J.; Ekbom, A.; Fraumeni, J.F., Jr. Pernicious anemia and subsequent cancer. A population-based cohort study. Cancer 1993, 71, 745-750. [CrossRef]

53. Dickey, W.; Kenny, B.D.; McMillan, S.A.; Porter, K.G.; McConnell, J.B. Gastric as well as duodenal biopsies may be useful in the investigation of iron deficiency anaemia. Scand. J. Gastroenterol. 1997, 32, 469-472. [CrossRef] [PubMed]

54. Ye, W.; Nyrén, O. Risk of cancers of the oesophagus and stomach by histology or subsite in patients hospitalised for pernicious anaemia. Gut 2003, 52, 938-941. [CrossRef]

55. Brinton, L.A.; Gridley, G.; Hrubec, Z.; Hoover, R.; Fraumeni, J.F. Cancer risk following pernicious anaemia. Br. J. Cancer 1989, 59, 810-813. [CrossRef]

56. Svendsen, J.H.; Dahl, C.; Svendsen, L.B.; Christiansen, P.M. Gastric cancer risk in achlorhydric patients. A long-term follow-up study. Scand. J. Gastroenterol. 1986, 21, 16-20. [CrossRef]

57. Landgren, A.M.; Landgren, O.; Gridley, G.; Dores, G.M.; Linet, M.S.; Morton, L.M. Autoimmune disease and subsequent risk of developing alimentary tract cancers among 4.5 million US male veterans. Cancer 2011, 117, 1163-1171. [CrossRef]

58. Pimentel-Nunes, P.; Libânio, D.; Marcos-Pinto, R.; Areia, M.; Leja, M.; Esposito, G.; Garrido, M.; Kikuste, I.; Megraud, F.; Matysiak-Budnik, T.; et al. Management of epithelial precancerous conditions and lesions in the stomach [MAPS II]: European Society of Gastrointestinal Endoscopy [ESGE], European Helicobacter and Microbiota Study Group [EHMSG], European Society of Pathology [ESP], and Sociedade Portuguesa de Endoscopia Digestiva [SPED] guideline update 2019. Endoscopy 2019, 51, 365-388.

59. Schade, S.G.; Cohen, R.J.; Conrad, M.E. Effect of hydrochloric acid on iron absorption. N. Engl. J. Med. 1968, 279, 672-674. [CrossRef]

60. Bezwoda, W.; Charlton, R.; Bothwell, T.; Torrance, J.; Mayet, F. The importance of gastric hydrochloric acid in the absorption of nonheme food iron. J. Lab. Clin. Med. 1978, 92, 108-116.

61. Birgegård, G.; Henry, D.; Glaspy, J.; Chopra, R.; Thomsen, L.L.; Auerbach, M. A Randomized Noninferiority Trial of Intravenous Iron Isomaltoside versus Oral Iron Sulfate in Patients with Nonmyeloid Malignancies and Anemia Receiving Chemotherapy: The PROFOUND Trial. Pharmacotherapy 2016, 36, 402-414. [CrossRef] [PubMed] 
62. Okam, M.M.; Koch, T.A.; Tran, M.-H. Iron Supplementation, Response in Iron-Deficiency Anemia: Analysis of Five Trials. Am. J. Med. 2017, 130, 991.e1-991.e8. [CrossRef] [PubMed]

63. Wang, H.; Li, L.; Qin, L.L.; Song, Y.; Vidal-Alaball, J.; Liu, T.H. Oral vitamin B12 versus intramuscular vitamin B12 for vitamin B12 deficiency. Cochrane Database Syst. Rev. 2018, 3, CD004655. [PubMed]

64. The Microbiome and Gastric Cancer: An Update [Internet]. Microb. Health Dis. 2020. Available online: https://www.microbiotajournal.com/article/267 (accessed on 25 July 2020).

65. Rajilic-Stojanovic, M.; Figueiredo, C.; Smet, A.; Hansen, R.; Kupcinskas, J.; Rokkas, T.; Andersen, L.; Machado, J.C.; Ianiro, G.; Gasbarrini, A.; et al. Systematic review: Gastric microbiota in health and disease. Aliment. Pharmacol. Ther. 2020, 51, 582-602. [CrossRef]

66. Tricker, A.R.; Preussmann, R. Carcinogenic N-nitrosamines in the diet: Occurrence, formation, mechanisms and carcinogenic potential. Mutat. Res. 1991, 259, 277-289. [CrossRef]

67. Yang, I.; Woltemate, S.; Piazuelo, M.B.; Bravo, L.E.; Yepez, M.C.; Romero-Gallo, J.; Delgado, A.G.; Wilson, K.T.; Peek, R.M.; Correa, P.; et al. Different gastric microbiota compositions in two human populations with high and low gastric cancer risk in Colombia. Sci. Rep. 2016, 6, 18594. [CrossRef]

68. Agents Classified by the IARC Monographs, Volumes 1-125-IARC Monographs on the Identification of Carcinogenic Hazards to Humans [Internet]. Available online: https://monographs.iarc.fr/agents-classifiedby-the-iarc/ (accessed on 24 June 2020).

69. Osato, M.S.; Gutierrez, O.; Kim, J.G.; Steinbach, G.; Graham, D.Y. Microflora of gastric biopsies from patients with duodenal ulcer and gastric cancer: A comparative study of patients from Korea, Colombia, and the United States. Dig. Dis. Sci. 1998, 43, 2291-2295. [CrossRef]

70. Bik, E.M.; Eckburg, P.B.; Gill, S.R.; Nelson, K.E.; Purdom, E.A.; Francois, F.; Perez-Perez, G.; Blaser, M.J.; Relman, D.A. Molecular analysis of the bacterial microbiota in the human stomach. Proc. Natl. Acad. Sci. USA 2006, 103, 732-737. [CrossRef]

71. Barber, M.; Franklin, R.H. Bacteriology of stomach and duodenum in cases of peptic ulcer and gastric carcinoma. Br. Med. J. 1946, 1, 951-953. [CrossRef]

72. Engstrand, L.; Graham, D.Y. Microbiome and Gastric Cancer. Dig. Dis. Sci. 2020, 65, 865-873. [CrossRef]

73. Vartoukian, S.R.; Palmer, R.M.; Wade, W.G. Strategies for culture of 'unculturable' bacteria. FEMS Microbiol. Lett. 2010, 309, 1-7. [CrossRef] [PubMed]

74. Loman, N.J.; Constantinidou, C.; Chan, J.Z.M.; Halachev, M.; Sergeant, M.; Penn, C.W.; Robinson, E.R.; Pallen, M.J. High-throughput bacterial genome sequencing: An embarrassment of choice, a world of opportunity. Nat. Rev. Microbiol. 2012, 10, 599-606. [CrossRef] [PubMed]

75. Human Microbiome Project Consortium. A framework for human microbiome research. Nature 2012, 486, 215-221. [CrossRef] [PubMed]

76. Monstein, H.-J.; Tiveljung, A.; Kraft, C.H.; Borch, K.; Jonasson, J. Profiling of bacterial flora in gastric biopsies from patients with Helicobacter pylori-associated gastritis and histologically normal control individuals by temperature gradient gel electrophoresis and $16 \mathrm{~S}$ rDNA sequence analysis. J. Med. Microbiol. 2000, 49, 817-822. [CrossRef] [PubMed]

77. Andersson, A.F.; Lindberg, M.; Jakobsson, H.; Bäckhed, F.; Nyrén, P.; Engstrand, L. Comparative analysis of human gut microbiota by barcoded pyrosequencing. PLoS ONE 2008, 3, e2836. [CrossRef] [PubMed]

78. Li, T.H.; Qin, Y.; Sham, P.C.; Lau, K.S.; Chu, K.-M.; Leung, W.K. Alterations in Gastric Microbiota after H. Pylori Eradication and in Different Histological Stages of Gastric Carcinogenesis. Sci. Rep. 2017, 7, 44935. [CrossRef]

79. Liu, Z.; Lozupone, C.; Hamady, M.; Bushman, F.D.; Knight, R. Short pyrosequencing reads suffice for accurate microbial community analysis. Nucleic Acids Res. 2007, 35, e120. [CrossRef]

80. Wu, W.M.; Yang, Y.S.; Peng, L.H. Microbiota in the stomach: New insights. J. Dig. Dis. 2014, $15,54-61$. [CrossRef]

81. Schulz, C.; Schütte, K.; Koch, N.; Vilchez-Vargas, R.; Wos-Oxley, M.L.; Oxley, A.P.A.; Vital, M.; Malfertheiner, P.; Piepe, D.H. The active bacterial assemblages of the upper GI tract in individuals with and without Helicobacter infection. Gut 2018, 67, 216-225. [CrossRef]

82. Wang, L.-L.; Yu, X.-J.; Zhan, S.-H.; Jia, S.-J.; Tian, Z.-B.; Dong, Q.-J. Participation of microbiota in the development of gastric cancer. World J. Gastroenterol. 2014, 20, 4948-4952. [CrossRef]

83. Bravo, D.; Hoare, A.; Soto, C.; Valenzuela, M.A.; Quest, A.F. Helicobacter pylori in human health and disease: Mechanisms for local gastric and systemic effects. World J. Gastroenterol. 2018, 24, 3071-3089. [CrossRef] 
84. Coker, O.O.; Dai, Z.; Nie, Y.; Zhao, G.; Cao, L.; Nakatsu, G.; Wu, W.K.K.; Wong, S.H.; Chen, Z.; Sung, J.J.Y.; et al. Mucosal microbiome dysbiosis in gastric carcinogenesis. Gut 2018, 67, 1024-1032. [CrossRef] [PubMed]

85. Ferreira, R.M.; Pereira-Marques, J.; Pinto-Ribeiro, I.; Costa, J.L.; Carneiro, F.; Machado, J.C.; Figueiredo, C. Gastric microbial community profiling reveals a dysbiotic cancer-associated microbiota. Gut 2018, 67, 226-236. [CrossRef] [PubMed]

86. Khosravi, Y.; Dieye, Y.; Poh, B.H.; Ng, C.G.; Loke, M.F.; Goh, K.L.; Vadivelu, J. Culturable bacterial microbiota of the stomach of Helicobacter pylori positive and negative gastric disease patients. Sci. World J. 2014, 2014, 610421. [CrossRef] [PubMed]

87. Yin, X.-H.; Wang, Y.-D.; Luo, H.; Zhao, K.; Huang, G.-L.; Luo, S.-Y.; Peng, J.X.; Song, J.K. Association between Tooth Loss and Gastric Cancer: A Meta-Analysis of Observational Studies. PLoS ONE 2016, 11, e0149653. [CrossRef]

88. Jo, H.J.; Kim, J.; Kim, N.; Park, J.H.; Nam, R.H.; Seok, Y.-J.; Kim, Y.R.; Kim, J.S.; Kim, J.M.; Kim, J.M.; et al. Analysis of Gastric Microbiota by Pyrosequencing: Minor Role of Bacteria Other Than Helicobacter pylori in the Gastric Carcinogenesis. Helicobacter 2016, 21, 364-374. [CrossRef]

89. Castaño-Rodríguez, N.; Goh, K.-L.; Fock, K.M.; Mitchell, H.M.; Kaakoush, N.O. Dysbiosis of the microbiome in gastric carcinogenesis. Sci. Rep. 2017, 7, 15957. [CrossRef]

90. Thorell, K.; Bengtsson-Palme, J.; Liu, O.H.-F.; Palacios Gonzales, R.V.; Nookaew, I.; Rabeneck, L.; Paszat, L.; Graham, D.Y.; Nielsen, J.; Lundin, S.B.; et al. In Vivo Analysis of the Viable Microbiota and Helicobacter pylori Transcriptome in Gastric Infection and Early Stages of Carcinogenesis. Infect. Immun. 2017, 85. [CrossRef]

Publisher's Note: MDPI stays neutral with regard to jurisdictional claims in published maps and institutional affiliations. 